\title{
Delinquent Subcultures: Sociological Interpretations of Gang Delinquency
}

\author{
By David J. Bordua
}

\begin{abstract}
Group delinquency has been of theoretical interest to American sociology for more than half a century. During that time, four major interpretations of the origins of gang delinquency and delinquent subcultures have emerged. The classical view developed by Thrasher focuses on the development of spontaneous groups under conditions of weak social control and social disorganization. Two other views, somewhat akin, emphasize the adjustment problems of lower class boys and stress respectively the status deprivation of such boys when they fail to place well according to the middle class measuring rod and the alienation produced when opportunities to achieve universally demanded success goals are denied lower class boys. Another view is that of the lower class street gang and its way of life as the adolescent version of a more general adult life style, namely, lower class culture. There is a noticeable tendency in the recent theories to emphasize irrational explanations of gang delinquency, to view the boys who participate as driven rather than attracted, and polemical pressures have tended to produce extreme theoretical interpretations.
\end{abstract}

David J. Bordua, Ph.D., Ann Arbor, Michigan, is Assistant Professor in the Department of Sociology at the University of Michigan. He received his doctorate from Harvard in 1957 and has published on theories of delinquency, authoritarianism, college aspirations of high school youth, and the use of formal selection instruments to detect delinquents at an early age. 
TVE problem of group delinquency has been a subject of theoretical interest for American sociologists and other social observers for well over a half century. In the course of that period, the group nature of delinquency has come to be a central starting point for many theories of delinquency, and delinquency causation has been seen by some sociologists as pre-eminently a process whereby the individual becomes associated with a group which devotes some or all of its time to planning, committing, or celebrating delinquencies and which has elaborated a set of lifeways -a subculture-which encourages and justifies behavior defined as delinquent by the larger society.

In addition to the processes whereby an individual takes on the beliefs and norms of a pre-existing group and thereby becomes delinquent-a process mysterious enough in itself in many cases - there is the more basic, and in many respects more complex, problem of how such groups begin in the first place. What are the social conditions that facilitate or cause the rise of delinquency-carrying groups? What are the varying needs and motives satisfied in individuals by such groups? What processes of planned social control might be useable in preventing the rise of such groups or in redirecting the behavior and moral systems of groups already in existence? All these questions and many others have been asked for at least two generations. Within the limits of this brief paper, it is impossible to present and analyze in detail the many answers to these questions which have been put forward by social scientists. What I can do is single out a few of the major viewpoints and concentrate on them.

In its more well-developed and extreme forms, gang or subcultural delinquency has been heavily concentrated in the low status areas of our large cities.
The theoretical interpretations I will discuss all confine themselves to gang delinquency of this sort.

\section{The Classical View}

Still the best book on gangs, gang delinquency, and-though he did not use the term-delinquent subcultures is The Gang by Frederick M. Thrasher, and his formulations are the ones that I have labeled "the classical view." Not that he originated the basic interpretative framework, far from it, but his application of the theoretical materials available at the time plus his sensitivity to the effects of social environment and his willingness to consider processes at all behavioral levels from the basic needs of the child to the significance of the saloon, from the nature of city government to the crucial importance of the junk dealer, from the consequences of poverty to the nature of leadership in the gang still distinguish his book. ${ }^{1}$

Briefly, Thrasher's analysis may be characterized as operating on the following levels. The ecological processes which determine the structure of the city create the interstitial area characterized by a variety of indices of conflict, disorganization, weak family and neighborhood controls, and so on. In these interstitial areas, in response to universal childhood needs, spontaneous play groups develop. Because of the relatively uncontrolled nature of these groups-or of many of them at leastand because of the presence of many attractive and exciting opportunities for fun and adventure, these groups engage in a variety of activities, legal and illegal, which are determined, defined, and directed by the play group itself rather than by conventional adult supervision.

The crowded, exciting slum streets teem with such groups. Inevitably, in

\footnotetext{
1 Frederick M. Thrasher, The Gang (Chicago: University of Chicago Press, 1927).
} 
a situation of high population density, limited resources, and weak social control, they come into conflict with each other for space, playground facilities, reputation. Since many of their activities, even at an early age, are illegal, although often not feloniously sothey swipe fruit from peddlers, turn over garbage cans, stay away from home all night and steal milk and cakes for breakfast, play truant from schoolthey also come into conflict with adult authority. Parents, teachers, merchants, police, and others become the natural enemies of this kind of group and attempt to control it or to convert it to more conventional activities. With some groups they succeed, with some they do not.

If the group continues, it becomes part of a network of similar groups, increasingly freed from adult restraint, increasingly involved in intergroup conflict and fighting, increasingly engaged in illegal activities to support itself and to continue to receive the satisfactions of the "free" life of the streets. Conflict, especially with other groups, transforms the play group into the gang. Its illegal activities become more serious, its values hardened, its structure more determined by the necessity to maintain eternal vigilance in a hostile environment.

By middle adolescence, the group is a gang, often with a name, usually identified with a particular ethnic or racial group, and usually with an elaborate technology of theft and other means of self-support. Gradually, the gang may move in the direction of adult crime, armed robbery, perhaps, or other serious crimes.

Prior to that time, however, it is likely to have engaged in much stealing from stores, railroad cars, empty houses, parents, drunks, almost anywhere money or goods are available. The ready access to outlets for stolen goods is of major importance here. The junk dealer, especially the junk wagon peddler, the convenient no-questions-asked attitudes of large numbers of local adults who buy "hot" merchandise, and the early knowledge that customers are available all help to make theft easy and profitable as well as morally acceptable. ${ }^{2}$

\section{Nonutilitarian?}

It is appropriate at this point to deal with a matter that has become important in the discussion of more recent theories of group delinquency. This is Albert K. Cohen's famous characterization of the delinquent subculture as nonutilitarian, by which he seems to mean that activities, especially theft, are not oriented to calculated economic ends. ${ }^{3}$

Thrasher makes a great point of the play and adventure quality of many illegal acts, especially in the pregang stages of a group's development, but he also describes many cases where theft has a quite rational and instrumental nature, even at a fairly early age.

The theft activities and the disposition of the loot make instrumental sense in the context of Thrasher's description of the nature of the group or gang. Much theft is essentially for the purpose of maintaining the group in a state of freedom from adult authority. If a group of boys lives days or even weeks away from home, then the theft of food

2 One of the charms of Thrasher's old-time sociology is the fashion in which fact intrudes itself upon the theorizing. For example, he tells us that there were an estimated 1,700 to 1,800 junk wagon men in Chicago, most of whom were suspected of being less than rigid in inquiring about the source of "junk." Ibid., p. 148. He also does some other things that seem to have gone out of style, such as presenting information on the age and ethnic composition of as many of the 1,313 gangs as possible. Ibid., pp. 73, 74, 191-193.

${ }^{3}$ Albert K. Cohen, Delinquent Boys: The Culture of the Gang (Glencoe: The Free Press, 1955), pp. 25, 26. 
or of things which are sold to buy food is hardly nonutilitarian. If such a group steals from freight cars, peddles the merchandise to the neighbors for movie money, and so on, this can hardly be considered nonutilitarian. The behavior makes sense as instrumental behavior, however, only after one has a picture of the general life led by the group. Boys who feed themselves by duplicating keys to bakery delivery boxes, creep out of their club rooms right after delivery, steal the pastry, pick up a quart of milk from a doorstep, and then have breakfast may not have a highly developed sense of nutritional values, but this is not nonutilitarian.

Such youngsters may, of course, spend the two dollars gained from selling stolen goods entirely on doughnuts and gorge themselves and throw much of the food away. I think this largely indicates that they are children, not that they are nonutilitarian. ${ }^{4}$

4 The examples cited above are all in Thrasher along with many others of a similar nature. In general, views of the nature of gang activity have shifted quite fundamentally toward a more irrationalist position. Thus, the gang's behavior seems to make no sense. Underlying this shift is a tendency to deal almost entirely with the gang's subculture, its values, beliefs, and the like, to deal with the relationships between this subculture and presumed motivational states which exist in the potential gang members before the gang or protogang is formed, and to deal very little with the developmental processes involved in the formation of gangs. Things which make no sense without consideration of the motivational consequences of gang membership are not necessarily so mysterious given Thrasher's highly sensitive analysis of the ways in which the nature of the gang as a group led to the development-in relation to the local environment-of the gang culture. Current theory focuses so heavily on motive and culture to the exclusion of group process that some essential points are underemphasized. It would not be too much of a distortion to say that Thrasher saw the delinquent subculture as the way of life that would be developed by a group becoming a gang and that some recent theorists look at the gang as the kind of group
Let us look a little more systematically at the Thrasher formulations, however, since such an examination can be instructive in dealing with the more recent theories. The analysis proceeds at several levels, as I have mentioned.

\section{Levels of analysis}

At the level of the local adult community, we may say that the social structure is permissive, attractive, facilitative, morally supportive of the gang development process.

It is permissive because control over children is weak; attractive because many enjoyable activities are available, some of which are illegal, like stealing fruit, but all of which can be enjoyed only if the child manages to evade whatever conventional controls do exist.

In another sense, the local environment is attractive because of the presence of adult crime of a variety of kinds ranging from organized vice to older adolescents and adults making a living by theft. The attraction lies, of course, in the fact that these adults may have a lot of money and live the carefree life and have high status in the neighborhood.

The local environment is facilitative in a number of ways. There are things readily available to steal, people to buy them, and places to hide without adult supervision.

The environment is morally supportive because of the presence of adult crime, as previously mentioned, but also for several additional reasons. One is the readiness of conventional adults to buy stolen goods. Even parents were discovered at this occasionally. The prevalence of political pull, which not only objectively protected adult crime but tended to undercut the norms against crime, must be mentioned then as now. The often bitter poverty which

that would develop if boys set about creating a delinquent subculture. 
turned many situations into matters of desperate competition also contributed.

Additionally, many gang activities, especially in the protogang stage, are not seriously delinquent and receive adult approval. These activities include such things as playing baseball for "side money" and much minor gambling such as penny pitching. Within limits, fighting lies well within the local community's zone of tolerance, especially when it is directed against members of another ethnic group.

At the level of the adolescent and preadolescent groups themselves, the environment is essentially coercive of gang formation. The presence of large numbers of groups competing for limited resources leads to conflict, and the fullfledged adolescent gang is pre-eminently a conflict group with a high valuation of fighting skill, courage, and similar qualities. Thus, the transition from spontaneous group to gang is largely a matter of participating in the struggle for life of the adolescent world under the peculiar conditions of the slum.

At the level of the individual, Thrasher assumes a set of basic needs common to all children. $\mathrm{He}$ leans heavily on the famous four wishes of W. I. Thomas, security, response, recognition, and new experience, especially the last two. Gang boys and boys in gang areas are, in this sense, no different from other boys. They come to choose different ways of satisfying these needs. What determines which boys form gangs is the differential success of the agencies of socialization and social control in channeling these needs into conventional paths. Thus, due to family inadequacy or breakdown or school difficulties, coupled with the ever present temptations of the exciting, adventurous street as compared to the drab, dull, and unsatisfying family and school, some boys are more available for street life than others.
Finally, it should be pointed out that the gang engages in many activities of a quite ordinary sort. Athletics are very common and highly regarded at all age levels. Much time is spent simply talking and being with the gang. The gang's repertory is diverse-baseball, football, dice, poker, holding dances, shooting the breeze, shoplifting, rolling drunks, stealing cars.

This is more than enough to give the tenor of Thrasher's formulations. I have purposely attempted to convey the distinctive flavor of essentially healthy boys satisfying universal needs in a weakly controlled and highly seductive environment. Compared to the deprived and driven boys of more recent formulations with their status problems, blocked opportunities (or psychopathologies if one takes a more psychiatric view), Thrasher describes an age of innocence indeed.

This is, perhaps, the most important single difference between Thrasher and some-not all-of the recent views. Delinquency and crime were attractive, being a "good boy" was dull. They were attractive because they were fun and were profitable and because one could be a hero in a fight. Fun, profit, glory, and freedom is a combination hard to beat, particularly for the inadequate conventional institutions that formed the competition.

\section{Working Class Boy and Middle Class Measuring Rod}

If Thrasher saw the gang as being formed over time through the attractiveness of the free street life and the unattractiveness and moral weakness of the agencies of social control, Albert $\mathbf{K}$. Cohen sees many working class boys as being driven to develop the delinquent subculture as a way of recouping the self-esteem destroyed by middle-classdominated institutions.

Rather than focusing on the gang and 
its development over time, Cohen's theory focuses on the way of life of the gang-the delinquent subculture. A collective way of life, a subculture, develops when a number of people with a common problem of adjustment are in effective interaction, according to Cohen. The bulk of his basic viewpoint is the attempted demonstration that the common problem of adjustment of the lower class gang boys who are the carriers of the delinquent subculture derives from their socialization in lower class families and their consequent lack of preparation to function successfully in middle class institutions such as the school.

The institutions within which the working class boy must function reward and punish him for acceptable or unacceptable performance according to the child-assessing version of middle class values. The middle class value pattern places great emphasis on ambition as a cardinal virtue, individual responsibility (as opposed to extreme emphasis on shared kin obligations, for example), the cultivation and possession of skills, the ability to postpone gratification, rationality, the rational cultivation of manners, the control of physical aggression and violence, the wholesome and constructive use of leisure, and respect for property (especially respect for the abstract rules defining rights of access to material things).$^{5}$

The application of these values adapted to the judgment of children constitutes the "middle class measuring rod" by which all children are judged in institutions run by middle class personnel-the school, the settlement house, and the like. The fact that working class children must compete according to these standards is a consequence of what Cohen, in a most felicitous phrase, refers to as the "democratic status universe" characteristic of American society. Everyone is expected to strive,

${ }^{5}$ Albert K. Cohen, op. cit., pp. 88-93. and everyone is measured against the same standard. Not everyone is equally prepared, however, and the working class boy is, with greater statistical frequency than the middle class boy, ill prepared through previous socialization.

\section{Cultural setting}

Social class for Cohen is not simply economic position but, much more importantly, a set of more or less vertically layered cultural settings which differ in the likelihood that boys will be taught the aspirations, ambitions, and psychological skills necessary to adjust to the demands of the larger institutions.

Cohen goes on to describe this predominantly lower working class cultural setting as more likely to show restricted aspirations, a live-for-today orientation toward consumption, a moral view which emphasizes reciprocity within the kin and other primary groups and correlatively less concern with abstract rules which apply across or outside of such particularistic circumstances. In addition, the working class child is less likely to be surrounded with educational toys, less likely to be trained in a family regimen of order, neatness, and punctuality. Of particular importance is the fact that physical aggression is more prevalent and more valued in the working class milieu.

When a working class boy thus equipped for life's struggle begins to function in the school, the settlement, and other middle-class-controlled institutions and encounters the middle class measuring rod, he inevitably receives a great deal of disapproval, rejection, and punishment. In short, in the eyes of the middle class evaluator, he does not measure up. This is what Cohen refers to as the problem of status deprivation which constitutes the fundamental problem of adjustment to which the delinquent subculture is a solution. 


\section{Self-derogation}

But this deprivation derives not only from the negative evaluations of others but also from self-derogation. The working class boy shares in this evaluation of himself to some degree for a variety of reasons. ${ }^{6}$ The first of these is the previously mentioned democratic status universe wherein the dominant culture requires everyone to compete against all comers. Second, the parents of working class boys, no matter how adjusted they seem to be to their low status position, are likely to project their frustrated aspirations onto their children. They may do little effective socialization to aid the child, but they are, nevertheless, likely at least to want their children to be better off than they are. Third, there is the effect of the mass media which spread the middle class life style. And, of course, there is the effect of the fact of upward mobility as visible evidence that at least some people can make the grade.

In short, the working class boy is subjected to many social influences which emphasize the fact that the way to respect, status, and success lies in conforming to the demands of middle class society. Even more importantly, he very likely has partly accepted the middle class measuring rod as a legitimate, even superior, set of values. The profound ambivalence that this may

6 In presenting the theoretical work of someone else, it is often the case that the views of the original author are simplified to his disadvantage. I have tried to guard against this. At this point in Cohen's formulation, however, I may be oversimplifying to his benefit. In view of the considerable struggle over the matter of just what the working class boy is sensitive to, I should point out that Cohen is less than absolutely clear. $\mathrm{He}$ is not as unclear, however, as some of his critics have maintained. For the best statement in Cohen's work, see Delinquent Boys, pp. 121-128. lead to in the individual is simply a reflection of the fact that the larger culture penetrates the lower working class world in many ways.

Thus, to the external status problem posed by devaluations by middle class functionaries is added the internal status problem of low self-esteem.

This, then, is the common problem of adjustment. Given the availability of many boys similarly situated, a collective solution evolves, the delinquent subculture. This subculture is characterized by Cohen as nonutilitarian, malicious, and negativistic, characterized by versatility, short-run hedonism, and an emphasis on group autonomy, that is, freedom from adult restraint.

These are, of course, the direct antitheses of the components of the middle class measuring rod. The delinquent subculture functions simultaneously to combat the enemy without and the enemy within, both the hated agents of the middle class and the gnawing internal sense of inadequacy and low selfesteem. It does so by erecting a counterculture, an alternative set of status criteria.

\section{Guilt}

This subculture must do more than deal with the middle-class-dominated institutions on the one hand and the feelings of low self-esteem on the other. It must also deal with the feelings of guilt over aggression, theft, and the like that will inevitably arise. It must deal with the fact that the collective solution to the common problem of adjustment is an illicit one in the eyes of the larger society and, certainly, also in the eyes of the law-abiding elements of the local area.

It must deal, also, with the increasing opposition which the solution arouses in the police and other agencies of the conventional order. Over time, 
the subculture comes to contain a variety of definitions of these agents of conventionality which see them as the aggressors, thus legitimating the group's deviant activities.

Because of this requirement that the delinquent subculture constitute a solution to internal, psychological problems of self-esteem and guilt, Cohen sees the group behavior pattern as being overdetermined in the psychological sense and as linking up with the mechanism of reaction formation.

Thus, the reason for the seeming irrationality of the delinquent subculture lies in the deeply rooted fears and anxieties of the status deprived boy. I have already discussed the shift from Thrasher's view of delinquency as attractive in a situation of weak social control to the views of it as more reactive held by some modern theorists. Cohen, of course, is prominent among these latter, the irrationalists. It is extremely difficult to bring these viewpoints together at all well except to point out that Cohen's position accords well with much research on school failure and its consequences in damaged self-esteem. It does seem unlikely, as I will point out later in another connection, that the failure of family, school, and neighborhood to control the behavior of Thrasher's boys would result in their simple withdrawal from such conventional contexts without hostility and loss of self-regard.

Cohen emphasizes that not all members of an ongoing delinquent group are motivated by this same problem of adjustment. Like any other protest movement, the motives which draw new members at different phases of its development will vary. It is sufficient that a core of members share the problem.

The analysis of the delinquent subculture of urban working class boys set forth in Delinquent Boys has been elaborated and supplemented in a later article by Cohen and James F. Short.?

\section{Other delinquent subcultures}

Responding to the criticism that there seemed a variety of kinds of delinquent subcultures, even among lower class urban youth, Cohen and Short distinguish the parent-male subculture, the conflict-oriented subculture, the drug addict subculture, and a subculture focused around semiprofessional theft. ${ }^{8}$

The parent subculture is the now familiar subculture described in Delinquent Boys. Cohen and Short describe it as the most common form. ${ }^{9}$

We refer to it as the parent sub-culture because it is probably the most common variety in this country-indeed, it might be called the "garden variety" of delinquent sub-culture-and because the characteristics listed above seem to constitute a common core shared by other important variants.

In discussing the conditions under which these different subcultures arise, Cohen and Short rely on a pivotal paper published in 1951 by Solomon Kobrin. ${ }^{10}$. Dealing with the differential location of the conflict-oriented versus the semiprofessional theft subculture, Kobrin pointed out that delinquency areas vary

7 Albert K. Cohen and James F. Short, Jr., "Research in Delinquent Sub-Cultures," Journal of Social Issues, Vol. 14 (1958), No, 3, pp. 20-36.

${ }^{8}$ For criticism in this vein as well as for the most searching general analysis of material from Delinquent Boys, see Harold L. Wilensky and Charles N. Lebeaux, Industrial Society and Social Welfare (New York: Russell Sage Foundation, 1958), Chap. 9.

${ }^{9}$ Cohen and Short, op. cit., p. 24. The characteristics are those of maliciousness and so on that I have listed previously.

10 Solomon Kobrin, "The Conflict of Values in Delinquency Areas," American Sociological Review, Vol. 16 (October 1951), No. 5, pp. 653-661. 
in the degree to which conventional and criminal value systems are mutually integrated. In the integrated area, adult criminal activity is stable and organized, and adult criminals are integral parts of the local social structure -active in politics, fraternal orders, providers of employment. Here delinquency can form a kind of apprenticeship for adult criminal careers with such careers being relatively indistinct from conventional careers. More importantly, the interests of organized criminal groups in order and a lack of police attention would lead to attempts to prevent the wilder and more untrammeled forms of juvenile violence. This would mean, of course, that crime in these areas was largely of the stable, profitable sort ordinarily associated with the rackets.

\section{Lower Class Boy and Lower Class Culture}

The interpretation of the delinquent subculture associated with Albert Cohen that I have just described contrasts sharply in its main features with what has come to be called the lower class culture view associated with Walter B. Miller. ${ }^{11}$ Miller disagrees with the Cohen position concerning the reactive nature of lower class gang culture. ${ }^{12}$

In the case of "gang" delinquency, the cultural system which exerts the most

${ }^{11}$ See the following papers, all by Walter $B$. Miller: "Lower Class Culture as a Generating Milieu of Gang Delinquency," Journal of Social Issues, Vol. 14 (1958), No. 3, pp. 5-19; "Preventive Work with Street Corner Groups: Boston Delinquency Project," The Annals of the American Academy of Political and Social Science, Vol. 322 (March 1959), pp. 97-106; "Implications of Urban Lower Class Culture for Social Work," The Social Service Review, Vol. 33 (September 1959), No. 3, pp. 219-236.

12 Walter B. Miller, "Lower Class Culture as a Generating Milieu of Gang Delinquency," op. cit., pp. 5, 6 . direct influences on behavior is that of the lower class community itself-a longestablished, distinctively patterned tradition with an integrity of its own-rather than a so-called "delinquent sub-culture" which has arisen through conflict with middle class culture and is oriented to the deliberate violation of middle class norms.

What, then, is the lower class culture Miller speaks of and where is it located? Essentially, Miller describes a culture which he sees as emerging from the shaking-down processes of immigration, internal migration, and vertical mobility. Several population and cultural streams feed this process, but, primarily, lower class culture represents the emerging common adaptation of unsuccessful immigrants and Negroes.

It is the thesis of this paper that from these extremely diverse and heterogeneous origins (with, however, certain common features), there is emerging a relatively homogeneous and stabilized native-American lower class culture; however, in many communities the process of fusion is as yet in its earlier phases, and evidences of the original ethnic or locality culture are still strong. ${ }^{13}$

In his analysis, Miller is primarily concerned with what he calls the hard

${ }^{13}$ Walter B. Miller, "Implications of Urban Lower Class Culture for Social Work," $o p$. cit., p. 225. Miller seems to be saying that the processes of sorting and segregating which characterized American industrial cities in the period referred to by Thrasher are beginning to show a product at the lower end of the status order. In this, as in several other ways, Miller is much more the inheritor of the classical view, as I have called it, than are Cohen or Cloward and Ohlin. Miller shows much the same concern for relatively wholistic description of the local community setting and much the same sensitivity to group process over time. Whether his tendency to see lower class culture in terms of a relatively closed system derives from differences in fact due to historical change or primarily to differences in theoretical perspective is hard to say. 
core group in the lower class - the same very bottom group referred to by Cohen as the lower-lower class. The properties of this emerging lower class culture as described by Miller may be divided into a series of social structural elements and a complex pattern of what Miller calls focal concerns.

\section{Focal concerns}

The first of the structural elements is what Miller calls the female-based household, that is, a family form wherein the key relationships are those among mature females (especially those of different generations but, perhaps, also sisters or cousins) and between these females and their children. The children may be by different men, and the biological fathers may play a very inconsistent and unpredictable role in the family. Most essentially, the family is not organized around the expectation of stable economic support provided by an adult male.

The relationship between adult females and males is characterized as one of serial mating, with the female finding it necessary repeatedly to go through a cycle of roles of mate-seeker, mother, and employee.

Closely related to and supportive of this form of household is the elaboration of a system of one-sex peer groups which, according to Miller, become emotional havens and major sources of psychic investment and support for both sexes and for both adolescents and adults. The family, then, is not the central focus of primary, intimate ties that it is in middle class circles.

In what is surely a masterpiece of cogent description, Miller presents the focal concerns of lower class culture as trouble, toughness, smartness, excitement, fate, and autonomy. His description of the complexly interwoven patterns assumed by these focal concerns cannot be repeated here, but a brief discussion seems appropriate. ${ }^{14}$

Trouble is what life gets you intoespecially trouble with the agents of the larger society. The central aspect of this focal concern is the distinction between law-abiding and law-violating behavior, and where an individual stands along the implied dimension either by behavior, reputation, or commitment is crucial in the evaluation of him by others. Toughness refers to physical prowess, skill, masculinity, fearlessness, bravery, daring. It includes an almost compulsive opposition to things seen as soft and feminine, including much middle class behavior, and is related, on the one hand, to sex-role identification problems which flow from the young boy's growing up in the female-based household and, on the other hand, to the occupational demands of the lower class world. Toughness, along with the emphasis on excitement and autonomy, is one of the ways one gets into trouble.

Smartness refers to the ability to "con," outwit, dupe, that is, to manipulate things and people to one's own advantage with a minimum of conventional work. Excitement, both as an activity and as an ambivalently held goal, is best manifested in the patterned cycle of the week end night-on-thetown complete with much drink and sexual escapades, thereby creating the risk of fighting and trouble. Between week ends, life is dull and passive. Fate refers to the perception by many lower class individuals that their lives are determined by events and forces over which they have little or no control. It manifests itself in widespread gambling

${ }^{14}$ This description of the focal concern is taken from Walter B. Miller, "Lower Class Culture as a Generating Milieu of Gang Delinquency," $o p$. cit., especially Chart 1, p. 7 . In this case especially, the original should be read. 
and fantasies of "when things break for me." Gambling serves multiple functions in the areas of fate, toughness, smartness, and excitement.

The last focal concern described by Miller is that of autonomy-concern over the amount, source, and severity of control by others. Miller describes the carrier of lower class culture as being highly ambivalent about such control by others. Overtly, he may protest bitterly about restraint and arbitrary interference while, covertly, he tends to equate coercion with care and unconsciously to seek situations where strong controls will satisfy nurturance needs.

\section{Growing $u p$}

What is it like to grow up in lower class culture? A boy spends the major part of the first twelve years in the company of and under the domination of women. He learns during that time that women are the people who count, that men are despicable, dangerous, and desirable. He also learns that a "real man" is hated for his irresponsibility and considered very attractive on Saturday night. He learns, too, that, if he really loves his mother, he will not grow up to be "just like all men" but that, despite her best efforts, his mother's pride and joy will very likely turn out to be as much a "rogue male" as the rest. In short, he has sex-role problems.

The adolescent street group is the social mechanism which enables the maturing boy to cope with a basic problem of feminine identification coupled with the necessity of somehow growing up to be an appropriately hated and admired male in a culture which maximizes the necessity to fit into all male society as an adult. The seeking of adult status during adolescence, then, has a particular intensity, so that manifestations of the adult culture's focal concerns tend to be overdone. In addition, the street group displays an exaggerated concern with status and belongingness which is common in all adolescent groups but becomes unusually severe for the lower class boy.

The street group, then, is an essential transition mechanism and training ground for the lower class boy. Some of the behavior involved is delinquent, but the degree to which the group engages in specifically delinquent acts, that is, constructs its internal status criteria around the law-violating end of the trouble continuum, may vary greatly depending on local circumstances. These include such things as the presence and salience of police, professional criminals, clergy, functioning recreational and settlement programs, and the like.

Like Thrasher, Miller emphasizes the wide range of activities of a nondelinquent nature that the gang members engage in, although, unlike Thrasher's boys, they do not do so because of poor social control, but because of the desire to be "real men."

Participation in the lower class street group may produce delinquency in several ways: ${ }^{15}$

1. Following cultural practices which comprise essential elements of the total pattern of lower class culture automatically violates certain legal norms.

2. In instances where alternative avenues to similar objectives are available, the nonlaw-abiding avenue frequently provides a greater and more immediate return for a relatively smaller investment of energy.

3. The "demanded" response to certain situations recurrently engendered within lower class culture involves the commission of illegal acts.

\section{Impact of middle class values}

Miller's approach, like the approaches of Thrasher and Cohen, has its strengths

\footnotetext{
${ }^{15}$ Walter B. Miller, "Lower Class Culture as a Generating Milieu of Gang Delinquency," op. cit., p. 18,
} 
and weaknesses. Miller has not been very successful in refuting Cohen's insistence on the clash between middle class and lower class standards as it affects the sources of self-esteem. To be sure, Cohen's own presentation of just what the lower class boy has or has not internalized is considerably confused. As I have remarked elsewhere, Cohen seems to be saying that a little internalization is a dangerous thing. ${ }^{16}$ Miller seems to be saying that the involvements in lower class culture are so deep and exclusive that contacts with agents of middle class dominated institutions, especially the schools, have no impact.

Actually, resolution of this problem does not seem so terribly difficult. In handling Cohen's formulations, I would suggest that previous internalization of middle class values is not particularly necessary, because the lower class boys will be told about them at the very time they are being status-deprived by their teachers and others. They will likely hate it and them (teachers and values), and the process is started. On the other hand, it seems unlikely that Miller's lower class boys can spend ten years in school without some serious outcomes. They should either come to accept middle class values or become even more antagonistic or both, and this should drive them further into the arms of lower class culture.

This would be especially the case because of the prevailing definition of school work as girlish, an attitude not at all limited to Miller's lower class culture. With the sex-role identification problems Miller quite reasonably poses for his boys, the demands of the middle class school teacher that he be neat and

${ }_{1.6}$ David J. Bordua, Sociological Theories and Their Implications for Juvenile Delinquency (Children's Bureau, Juvenile Delinquency: Facts and Facets, No. 2; Washington, D. C.: U. S. Government Printing Office, 1960), pp. 9-11. clean and well-behaved must be especially galling. ${ }^{17}$ In short, it seems to me inconceivable that the objective conflict between the boys and the school, as the most crucial example, could end in a simple turning away.

Miller also seems to be weak when he insists upon seeing what he calls the hard core of lower class culture as a distinctive form and, at the same time, must posit varieties of lower class culture to account for variations in behavior and values. This is not necessarily a factually untrue position, but it would seem to underemphasize the fluidity and variability of American urban life. It is necessary for him to point out that objectively low status urban groups vary in the degree to which they display the core features of lower class culture, with Negroes and Irish groups among those he has studied displaying it more and Italians less.

\section{Validity of female base}

Miller seems so concerned that the features of lower class culture, especially the female-based household, not be seen as the disorganization of the more conventional system or as signs of social pathology that he seems to overdo it rather drastically. He is very concerned to show that lower class culture is of ancient lineage and is or was functional in American society. Yet, at the same time, he says that lower class culture is only now emerging at the bottom of the urban heap. He also forgets that none of the low status groups in the society, with the possible exception of low status Negroes, has any history of

\footnotetext{
17 For evidence that lower class Negro girls seem to do much better than boys in adjusting to at least one middle class institution, see Martin Deutsch, Minority Group and Class Status as Related to Social and Personality Factors in School Achievement (Monograph No. 2, The Society for Applied Anthropology; Ithaca, New York: The Society, 1960).
} 
his female-based household, at least not in the extreme form that he describes. ${ }^{18}$

A closely related problem is posed by Miller's citation of cross-cultural evidence, for example, "The female-based household is a stabilized form in many societies-frequently associated with polygamy -and is found in 21 per cent of world societies." 19 I do not doubt the figure, but I question the implication that the female-based household as the household form, legitimated and normatively supported in societies prácticing polygamy, can be very directly equated with a superficially similar system existing on the margins of a larger society and clearly seen as deviant by that larger society. Surely, in primitive societies, the household can count on the stable economic and judicial base provided by an adult male. The very fact that such a household in the United States is under continuous and heavy pressure from the law, the Aid to Dependent Children worker, and nearly all other agents of the conventional order must make for a very different situation than in societies where it is the accepted form. In such societies, would mothers generally regard men as "unreliable and untrustworthy" and would the statement "all men are no good" be common? ${ }^{20}$ Surely, such an attitude implies some awareness that things should be otherwise.

All this is not to argue that tendencies of the sort Miller describes are not present nor to underestimate the value of his insistence that we look at this way of life in its own terms-a valuable contribution indeed-but only to ask for somewhat greater awareness

18 E. Franklin Frazer, The Negro Family in the United States (Chicago: University of Chicago Press, 1939).

19 Walter B. Miller, "Implications of Urban Lower Class Culture for Social Work," op. cit., p. 225 fn.

${ }^{20}$ Ibid., p. 226. of the larger social dynamics that produce his lower class culture.

\section{Danger of tautology}

Finally, a last criticism of Miller's formulations aims at the use of the focal concerns material. There seems more than a little danger of tautology here if the focal concerns are derived from observing behavior and then used to explain the same behavior. One would be on much safer ground to deal in much greater detail with the structural roots and reality situations to which lower class culture may be a response. Thus, for example, Miller makes no real use of the vast literature on the consequences of prolonged instability of employment, which seems to me the root of the matter.

These criticisms should not blind us to very real contributions in Miller's position. Most importantly, he tells us what the lower class street boys are for, rather than just what they are against. In addition, he deals provocatively and originally with the nature of the adult culture which serves as the context for adolescent behavior. Finally, he alerts us to a possible historical development that has received relatively little attention-the emergence of something like a stable American lower class. This possiblity seems to have been largely neglected in studies of our increasingly middle class society.

\section{Success Goals and Opportunity STRUCTURES}

The last of the major approaches to the problem of lower class group delinquency to be considered here is associated with Richard A. Cloward and Lloyd E. Ohlin..$^{21}$ Stated in its briefest

21 The full statement of the approach is in Richard A. Cloward and Lloyd E. Ohlin, Delinquency and Opportunity (Glencoe: The Free Press, 1960); see also Richard A. Cloward "Illegitimate Means, Anomie and 
form, the theory is as follows: American culture makes morally mandatory the seeking of success goals but differentially distributes the morally acceptable means to these success goals, the legitimate opportunities that loom so large in the approach. ${ }^{22}$

This gap between culturally universalized goals and structurally limited means creates strain among lower class youths who aspire to economic advancement. Such strain and alienation leads to the formation of delinquent subcultures, that is, normative and belief systems that specifically support and legitimate delinquency, among those boys who blame the system rather than themselves for their impending or actual failure. The particular form of delinquent subculture-conflict, criminal, or retreatist (drug-using) - which results depends on the nature of the local neighborhood and, especially, on the availability of illegitimate opportunities, such as stable crime careers as models and training grounds.

The criminal subculture develops in stable neighborhoods with much regularized crime present; the conflict form develops in really disorganized neighborhoods where not even illegitimate opportunities are available; the retreatist, or drug-use, subculture develops among persons who are double failures due either to internalized prohibitions against violence or theft or to the objective unavailability of these solutions.

Intervening between the stress due to blocked aspirations and the creation of the full-fledged subculture of whatever type is a process of collectively supported "withdrawal of attributions of legitimacy from established social norms."

Deviant Behavior," American Sociological Review, Vol. 24 (April 1959), No. 2, pp. 164-176.

${ }^{22}$ For the original version of this formulation, see Robert K. Merton, Social Theory and Social Structure (rev. and enl.; Glencoe: The Free Press, 1951), Chaps. 4, 5.
This process, coupled with the collective development of the relevant delinquent norms, serves to allay whatever guilt might have been felt over the illegal acts involved in following the delinquent norms.

Since the argument in Delinquency and Opportunity is, in many ways, even more complicated than those associated with Cohen, Short, and Miller, I will discuss only a few highlights. ${ }^{23}$

\section{Potential delinquents}

On the question of who aspires to what, which is so involved in the disagreements between Cohen and Miller, Cloward and Ohlin take the position that it is not the boys who aspire to middle class status - and, therefore, have presumably partially - internalized the middle class measuring rod-who form the raw material for delinquent subculture, but those who wish only to improve their economic status without any change in class membership. Thus, it is appropriate in their argument to say that the genitors of the delinquent sub. cultures are not dealing so much with an internal problem of self-esteem as with an external problem of injustice. Cohen says, in effect, that the delinquent subculture prevents self-blame for failure from breaking through, the reaction formation function of the delinquent subculture. Cloward and Ohlin say that the delinquent norm systems are generated by boys who have already

${ }^{23}$ Large segments of Delinquency and $O p$ portunity are devoted to refutations of other positions, especially those of Cohen and Miller. I felt that, at least for the present paper, criticizing in detail other people's refutations of third parties might be carrying the matter too far. It should be pointed out, however, that the tendency to take extreme positions as a consequence of involvement in a polemic which is apparent in Miller's work seems even more apparent in the Cloward and Ohlin book. 
determined that their failures, actual or impending, are the fault of the larger social order. ${ }^{24}$

This insistence that it is the "system blamers" who form the grist for the subcultural mill leads Cloward and Ohlin into something of an impasse, it seems to me. They must, of course, then deal with the determinants of the two types of blame and choose to say that two factors are primarily relevant. First, the larger culture engenders expectations, not just aspirations, of success which are not met, and, second, there exist highly visible barriers to the fulfillment of these expectations, such as racial prejudice, which are defined as unjust.

These do not seem unreasonable, and, in fact, in the case of Negro youth, perhaps, largely fit the case. Cloward and Ohlin, however, are forced for what seems overwhelmingly polemical reasons into a position that the feeling of injustice must be objectively correct. Therefore, they say (1) that it is among those actually fitted for success where the sense of injustice will flourish and (2) that delinquent subcultures are formed by boys who do not essentially differ in their capacity to cope with the larger institutions from other boys. This point deserves some attention since it is so diametrically opposed to the Cohen position which states that some working class boys, especially lower working class boys, are unable to meet the demands of middle-class-dominated institutions.

It is our impression that a sense of being unjustly deprived of access to opportunities to which one is entitled is common among those who become participants in

24 Richard A. Cloward and Lloyd E. Ohlin, Delinquency and Opportunity, op. cit. For the problem of types of aspiration and their consequences, see, especially, pp. 86-97. For the matter of self-blame and their system blame for failure, see pp. 110-126. delinquent subcultures. Delinquents tend to be persons who have been led to expect opportunities because of their potential ability to meet the formal, institutionallyestablished criteria of evaluation. Their sense of injustice arises from the failure of the system to fulfill these expectations. Their criticism is not directed inward since they regard themselves in comparison with their fellows as capable of meeting the formal requirements of the system. It has frequently been noted that delinquents take special delight in discovering hypocrisy in the operation of the established social order. They like to point out that it's "who you know, not what you know" that enables one to advance or gain coveted social rewards. They become convinced that bribery, blackmail, fear-inspiring pressure, special influence, and similar factors are more important than the publicly avowed criteria of merit. ${ }^{25}$

\section{Delinquents and nondelinquent peers}

On the same page in a footnote, the authors go on to say that the research evidence indicates "the basic endowments of delinquents, such as intelligence, physical strength, and agility, are the equal of or greater than those of their non-delinquent peers."

The material in these quotations is so riddled with ambiguities it is difficult to know where to begin criticism, but we can at least point out the following. First, Cloward and Ohlin seem to be confusing the justificatory function of delinquent subcultures with their causation. All of these beliefs on the part of gang delinquents have been repeatedly reported in the literature, but, by the very argument of Delinquency and Opportunity, it is impossible to tell whether they constitute compensatory ideology or descriptions of objective reality.

Second, Cloward and Ohlin seem to be victims of their very general tend-

${ }^{25}$ Ibid., p. 117. 
ency to ignore the life histories of their delinquents. ${ }^{28}$ Thus, there is no way of knowing really what these subcultural beliefs may reflect in the experience of the boys. Third, and closely related to the ignoring of life history material, is the problem of assessing the degree to which these gang boys are in fact prepared to meet the formal criteria for success. To say that they are intelligent, strong, and agile is to parody the criteria for advancement. Perhaps Cohen would point out that intelligent, agile, strong boys who begin the first grade using foul language, fighting among themselves, and using the school property as arts and crafts materials do not meet the criteria for advancement.

It is quite true that members of highly sophisticated delinquent gangs often find themselves blocked from whatever occupational opportunities there are, but this seems, often, the end product of a long history of their progressively cutting off opportunity and destroying their own capacities which may begin in the lower class family, as described by either Cohen or Miller, and continue through school failure and similar events. By the age of eighteen, many gang boys are, for all practical purposes, unemployable or need the support, instruction, and sponsorship of trained street-gang workers. Participation in gang delinquency in itself diminishes the fitness of many boys for effective

26 This is the most fundamental weakness in the book. The delinquents in Thrasher, Cohen, and Miller were, in varying degrees, once recognizably children. Cloward and Ohlin's delinquents seem suddenly to appear on the scene sometime in adolescence, to look at the world, and to discover, "Man, there's no opportunity in my structure." It is instructive in this connection to note that the index to Delinquency and Opportunity contains only two references to the family. One says that the family no longer conducts occupational training; the other criticizes Miller's ideas on the female-based household. functioning in the conventional world ${ }^{27}$ If, indeed, Cloward and Ohlin mean to include the more attitudinal and characterological criteria for advancement, then it seems highly unlikely that any large number of boys trained and prepared to meet these demands of the occupational world could interpret failure exclusively in terms which blame the system. They would have been too well socialized, and, if they did form a delinquent subculture, it would have to perform the psychological function of mitigating the sense of internal blame. This, of course, would make them look much like Cohen's boys.

In short, Cloward and Ohlin run the risk of confusing justification and causation and of equating the end with the beginning.

All of this is not to deny that there are real obstacles to opportunity for lower class boys. There are. These blocks on both the performance and learning sides, are a major structural feature in accounting for much of the adaptation of lower class populations. But they do not operate solely or even primarily on the level of the adolescent. They create a social world in which he comes of age, and, by the time he reaches adolescence, he may find himself cut off from the larger society. Much of the Cloward and Ohlin approach seems better as a theory of the origins of Miller's lower class culture. Each generation does not meet and solve anew the problems of class structure barriers to opportunity but begins with

${ }^{27}$ Here, again, Thrasher seems superior to some of the modern theorists. He stressed the fact that long-term involvement in the "free, undisciplined" street life with money at hand from petty theft and with the days devoted to play was not exactly ideal preparation for the humdrum life of the job. Again, Thrasher's sensitivity to the attitudinal and subcultural consequences of the gang formation and maintenance process truly needs reintroduction. 
the solution of its forebears. ${ }^{28}$ This is why reform efforts can be so slow to succeed.

\section{Some insights}

The positive contributions of the Cloward-Ohlin approach seem to me to lie less on the side of the motivational sources of subcultural delinquency, where I feel their attempts to clarify the ambiguities in Cohen have merely led to new ambiguities, but more on the side of the factors in local social structure that determine the type of subcultural delinquency.

The major innovation here is the concept of illegitimate opportunities which serves to augment Kobrin's almost exclusive emphasis on the differentially controlling impact of different slum environments. I do think that Cloward and Ohlin may make too much of the necessity for systematic, organized criminal careers in order for the illegitimate opportunity structure to have an effect, but the general argument has great merit.

In addition to the concept of illegitimate opportunities and closely related to it is the description, or speculation, concerning historical changes in the social organization of slums. Changes in urban life in the United States may have truly produced the disorganized slum devoid of the social links between young and old, between children and

28 Parenthetically, the Cloward and Ohlin position has great difficulty in accounting for the fact that lower class delinquent subculture carriers do not avail themselves of opportunities that do exist. The mixed success of vocational school training, for example, indicates that some fairly clear avenues of opportunity are foregone by many delinquent boys. For Negro boys, where avenues to the skilled trades may indeed be blocked, their argument seems reasonable. For white boys, I have serious question. In fact, the only really convincing case they make on the aspirationblockage, system-blame side is for Negroes. older adolescents which characterized the slums described by Thrasher. Certainly, the new conditions of life seem to have created new problems of growing up, though our knowledge of their precise impact leaves much to be desired.

\section{ConcLusion}

This paper should not, I hope, give the impression that current theoretical interpretations of lower class, urban, male subcultural delinquency are without value. Such is far from the case. Many of my comments have been negative since each of the theorists quite ably presents his own defense, which should be read in any case. In fact, I think that this problem has led to some of the most exciting and provocative intellectual interchange in all of sociology in recent years. I do believe, however, that this interchange has often been marred by unnecessary polemic and, even more, by a lack of relevant data.

As I have indicated, there have been some profound changes in the way social theorists view the processes of gang formation and persistence. These, I believe, derive only partially, perhaps even unimportantly, from changes in the facts to be explained. Indeed, we must wait for a study of gangs which will approach Thrasher's in thoroughness before we can know if there are new facts to be explained. Nor do I believe that the changes in viewpoint have come about entirely because old theories were shown to be inadequate to old facts. Both Cohen and Cloward and Ohlin feel that older theorists did not deal with the problem of the origins of delinquent subcultures, but only with the transmission of the subculture once developed. ${ }^{29}$

29 Albert K. Cohen, Delinquent Boys, op. cit., p. 18; Richard A. Cloward and Lloyd E, Ohlin, Delinquency and Opportunity, op. cit., p. 42 . 
A careful reading of Thrasher indicates that such is not the case.

All in all, though, it does not seem like much fun any more to be a gang delinquent. Thrasher's boys enjoyed themselves being chased by the police, shooting dice, skipping school, rolling drunks. It was fun. Miller's boys do have a little fun, with their excitement focal concern, but it seems so desperate somehow. Cohen's boys and Cloward and Ohlin's boys are driven by grim economic and psychic necessity into rebellion. It seems peculiar that modern analysts have stopped assuming that "evil" can be fun and see gang delinquency as arising only when boys are driven away from "good." so

${ }^{30}$ For a more thorough commentary on changes in the view of human nature which, I think, partly underlie the decline of fun in theories of the gang, see Dennis Wrong, "The Oversocialized View of Man," American Sociological Review, Vol. 26 (April 1961), No. 3, pp. 183-193. 